\title{
SURVEY OF IRRIGATION AREA USING MICRO UNMANNED AERIAL VEHICLE (MICRO-UAV) IN GUMBASA IRRIGATION AREA
}

\author{
Jabal Tarik Ibrahim ${ }^{1}$, Nugroho Tri Waskitho ${ }^{1}$, Wahono ${ }^{1}$, Sitti Rahma \\ Ma'mun $^{2}$ \\ ${ }^{1}$ Faculty of Agriculture and Animal Husbandry, University of Muhammadiyah Malang, Indonesia \\ ${ }^{2}$ Faculty of Agriculture, University of Muhammadiyah Kendari, Indonesia \\ *corresponding author: triwaskithon@yahoo.co.id
}

\begin{abstract}
This study aims to develop a new approach in doing evaluation of irrigation system in terms of getting accurate data at a reasonable cost in an essay and fast manner. The research was done at Gumbasa Irrigation District in Sigi, Central of Sulawesi, Indonesia on May-June 2015. The workflow consists of: (i) preparation; (ii) flight planning; (iii) automated flight; (iv) data processing. Data analysis was done by comparison between Red Green Blue (RGB) method and Near Infra Red Green Blue (NirGB) method. The results show that the use of micro-UAV provide an efficient way to collect data needed to manage a very large irrigation system. The RGB image can be effectively used to identify crop's condition on an irrigation area, which is needed to plan irrigation efficiently. The NirGB image can be effectively used to assess tertiary and secondary level of irrigation canal such as leakage.
\end{abstract}

Keywords: micro unmanned aerial vehicle, irrigation, RGB method, NirGB method

\section{INTRODUCTION}

Irrigation is one of the most important components of the agricultural development in Indonesia (Pasandaran, Simatupang, \& Faqi, 2006). The main concerns on irrigation management are its efficiency and effectiveness. Most of the problems are derived from the lack of accurate data of irrigation systems for conducting best management practices. Unmanned Aerial Vehicle development has promised a new way to collect important irrigation systems data in an efficient and effective manner. The UAV makes data collection can be done virtually anytime, anywhere at very reasonable cost. Some study has proven the potential use of UAV in agriculture, such as crop status mapping (Guo, Kujirai, \& Watanabe, 2012), vegetation sensing (Berni, Zarco-tejada, Suárez, González-dugo, \& Fereres, 2009), or soil erosion monitoring (Acevo-Herrera et al., 2010). MicroUAV has advantages which almost impossible to get from conventional aircraft. i.e: it can fly at a lower altitudes so it able to provide a higher resolution image needed by site-specific farm management (Huang, Thomson, Hoffmann, Lan, \& Fritz, 2013).
Managing irrigation system of paddy field is following a cycling steps starts from planning, operation, maintenance, monitoring, to evaluation and back to planning for the next season. The best start for improving an irrigation system is developing a good planning. However, reffering to the need of precise data in developing a good planning, the best start in improving running irrigation system is from evaluation step. The evaluation process will provide data for planning activities. The quality of data comes from evaluation activities, therefore, is a critical parameter for the whole irrigation management processes. A study on irrigation system based on airborne remote sensing found that it is possible to detect irrigation canal leakage (Huang, Fipps, Maas, \& Fletcher, 2010)

Huang et. al., work was based on conventional aircraft with a specialized imaging systems. While it gave a very good data for irrigation management purposes, it costs so much in term of operational and investment. This study aims to develop new approach in doing irrigation systems using a micro Unmanned Aerial Vehicle with modified consumer cameras. 


\section{RESEARCH METHODS}

\section{The research location}

The study area consisted of $84 \mathrm{Ha}$ area of paddy land covered by a secondary irrigation channel within Gumbasa Irrigation System, Central
Sulawesi, Indonesia (Figure 1). Gumbasa Irrigation System has 9,625 Ha potential area and 6.500 functional area.

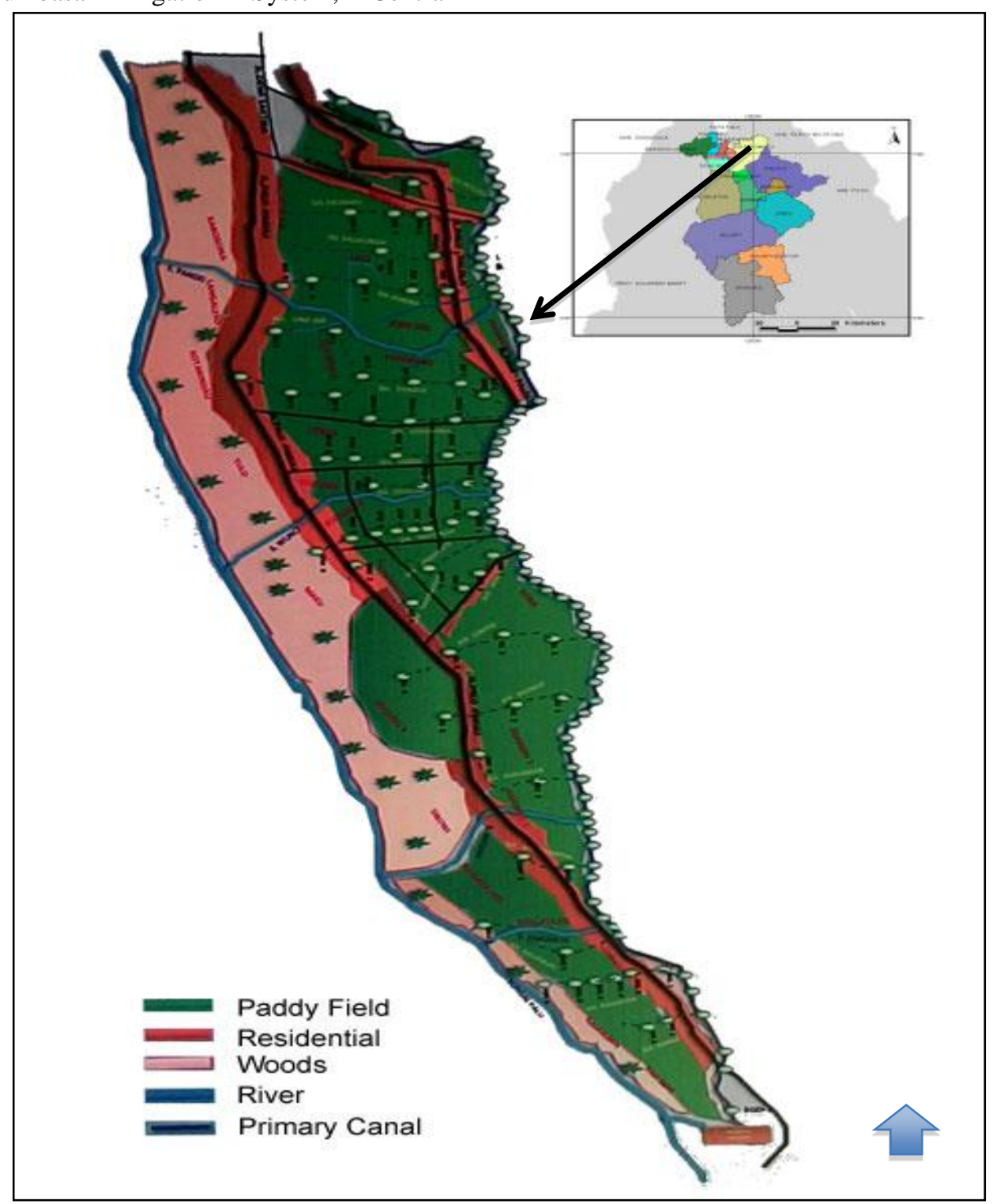

Figure 1. Map of the location

\section{Equipments}

\section{A. UAV}

The UAV platform used in this study is developed based on Skywalker 1900 airframe (Figure 2). The airframe is made from EPO foam with carbon enforcing spar. I has $1900 \mathrm{~mm}$ wingspan and equipped with $2 \times 5,000 \mathrm{mAH}$ battery at 14.8 volt. Total weight with $1 \mathrm{Kg}$ payload is $3.25 \mathrm{Kg}$ and capable to fly for more than 90 minutes. The platform is implementing an open source flight controller namely Ardu Pilot Mega 2.6 (APM 2.6). The controller provides many flight automation to the aircraft such as stabilized flight, return-tolaunch, auto take-off, auto landing, and automatic flight based on user defined waypoints. The aircraft also equipped with some sensors, i.e:

1. Air speed sensor

2. Global Position Systems and Magnetometer

3. Current sensor 


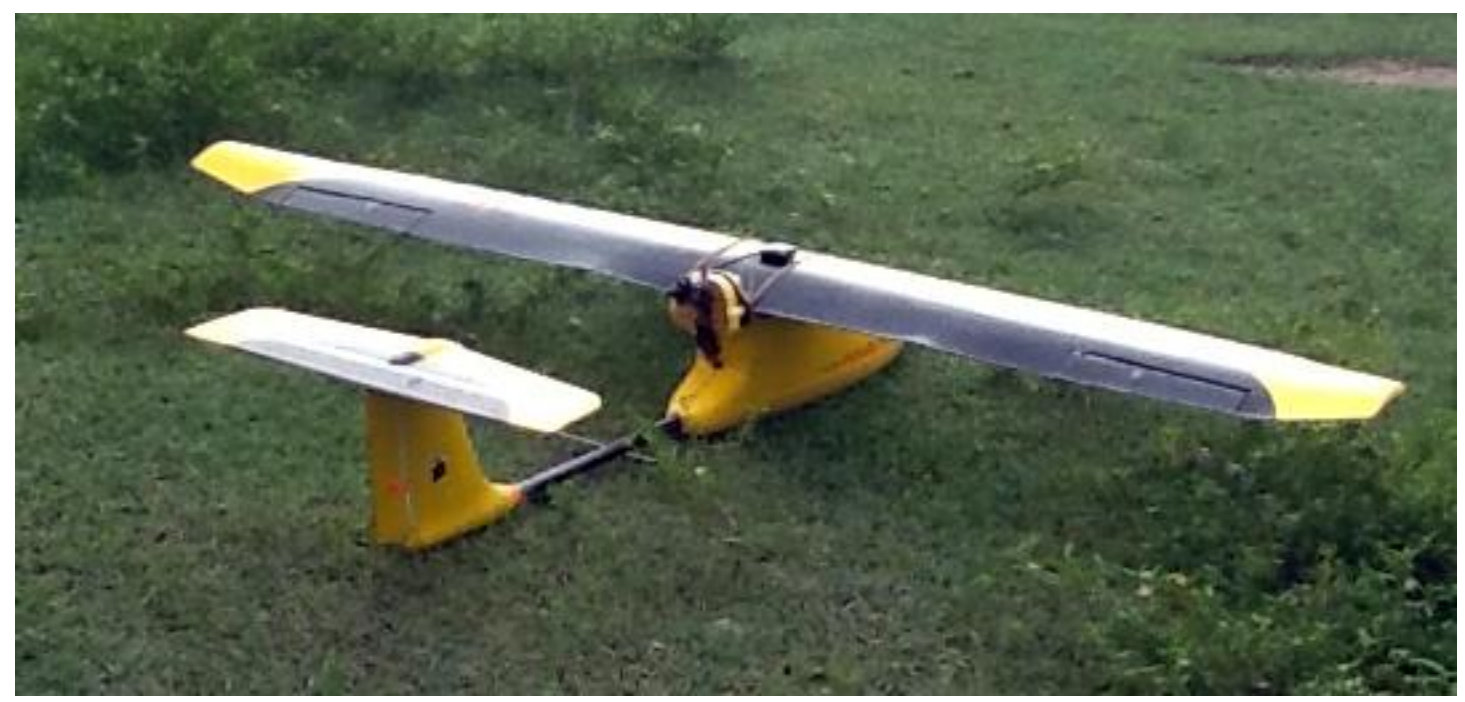

Figure 2. Micro-UAV

\section{Imaging Systems}

We used 2 Canon ${ }^{\circledR}$ S100 PowerShot digital camera (12 Mpix CMOS sensor) with $24 \mathrm{~mm}$ focal length: one with original spectral bands (RGB) and the other with modified Near Infra Red Filter (NirGB). The camera focus is set to infinite while the aperture sensitivity and shutter speed are determined by flight acquisition tests and adjusted manually to get the best picutre in term of sharpeness and light saturation. Camera shutting is controlled by a Canon Hackable Development Kit (CHDK) script to get a series of picture with certain time interval (intervalometer). The time interval is defined based on the speed of UAV flight which is determined during the flight planning in the field.

We used APM Mission Planner ${ }^{\circledR}$ V 3.14 to plan and control the UAV flight, Agisoft ${ }^{\circledR}$ Photoscan to produce orthophoto, and ImageJ to produce vegetation index.

\section{Workflow}

The study employed a general workflow for mapping which is similar to the one based on aerial mapping. The workflow consists of: (i) preparation; (ii) flight planning; (iii) automated flight; (iv) data processing. The first phase is preparation which includes area definition and hardware setup. The second phase is flight planning using Mission Planner® software. This step was done in the field to make the best plan based on real terrain and weather condition. We defined the time lapse interval of camera shutting in this phase. Below are flight and data acquisition parameters:

1. Altitude : $140 \mathrm{~m}$

2. Ground speed : $10 \mathrm{~m} /$ second

3. Shutting intervals: 3.9 seconds

4. Side overlap : $75 \%$

5. Forward overlap : $60 \%$

Flights were done automatically using waypoints defined on the flight planning phase. Flight controller recorded all of flight parameters into a $\log$ file which will be used to determine data acquisition parameter such as camera viewing angle, position and orientation of sensors.

Data collected from previous phase then processed using Photoscan ${ }^{\circledR}$ software to stiched images and get georeferenced-orthophoto. By using a single coordinate systems we can produce a stacked of multispectral image (NIR, Red, Green, Blue) and produce a Normalized Difference Vegetation Index (NDVI) using Image $\AA$ which is generated as:

$$
\mathrm{NDVI}=(\mathrm{NIR}-\mathrm{Red}) /(\mathrm{NIR}+\mathrm{Red})
$$

The georeferrenced-orthophoto. 


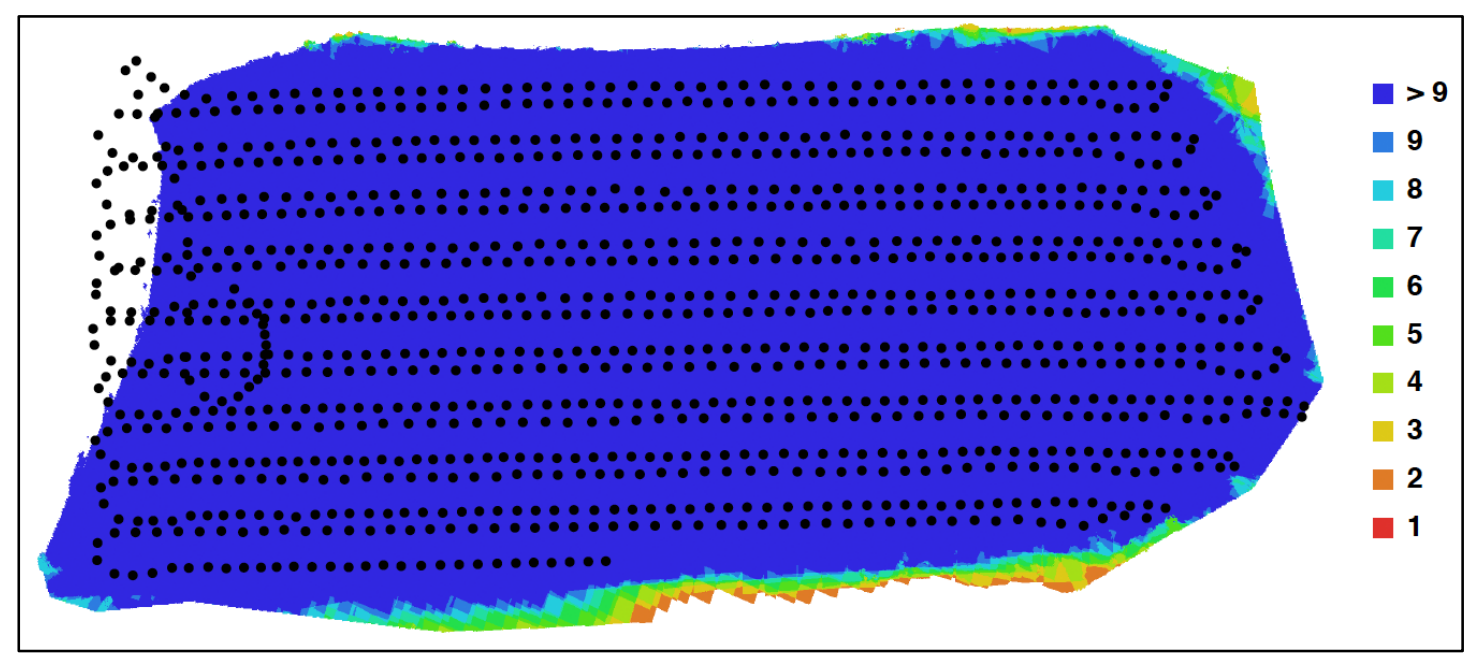

Figure Figure 3. Flight path, image data acquisition points, and number of overlaps

\section{RESULTS AND DISCUSSION}

On June 20, 2015, we conducted two flyovers; the first flight used a normal Red-Green-Blue (RGB) camera and the second flight used a modified Near Infra Red - Green - Blue (NirGB) camera. Both flights used the same flight plan. During 37 minutes of flight we acquired 1094 images (Figure 3) of each mission.

The georeferenced orthophoto produced from RGB images has $4.04 \mathrm{~cm}$ ground resolution and NirGB has $4.15 \mathrm{~cm}$ respectively. While the mission cover $155 \mathrm{Ha}$, the actual acreage of irrigation area surveyed was 87 ha and the rest is non irrigated area. These figures implied that on such weather and terrain situation the capability of micro-UAV to map is 251 Ha per hour.

The true color RGB images (Figure 4) provide an easy way to visually identify the field characteristics such as: crops planted, estimated paddy fenology stages and acreage. Those attributes are necessary to do best irrigation planning. The false color NirGB images (Figure 5) shows the easier way to identify irrigation networks and potentially to do its assessment as well as irrigation leakage.

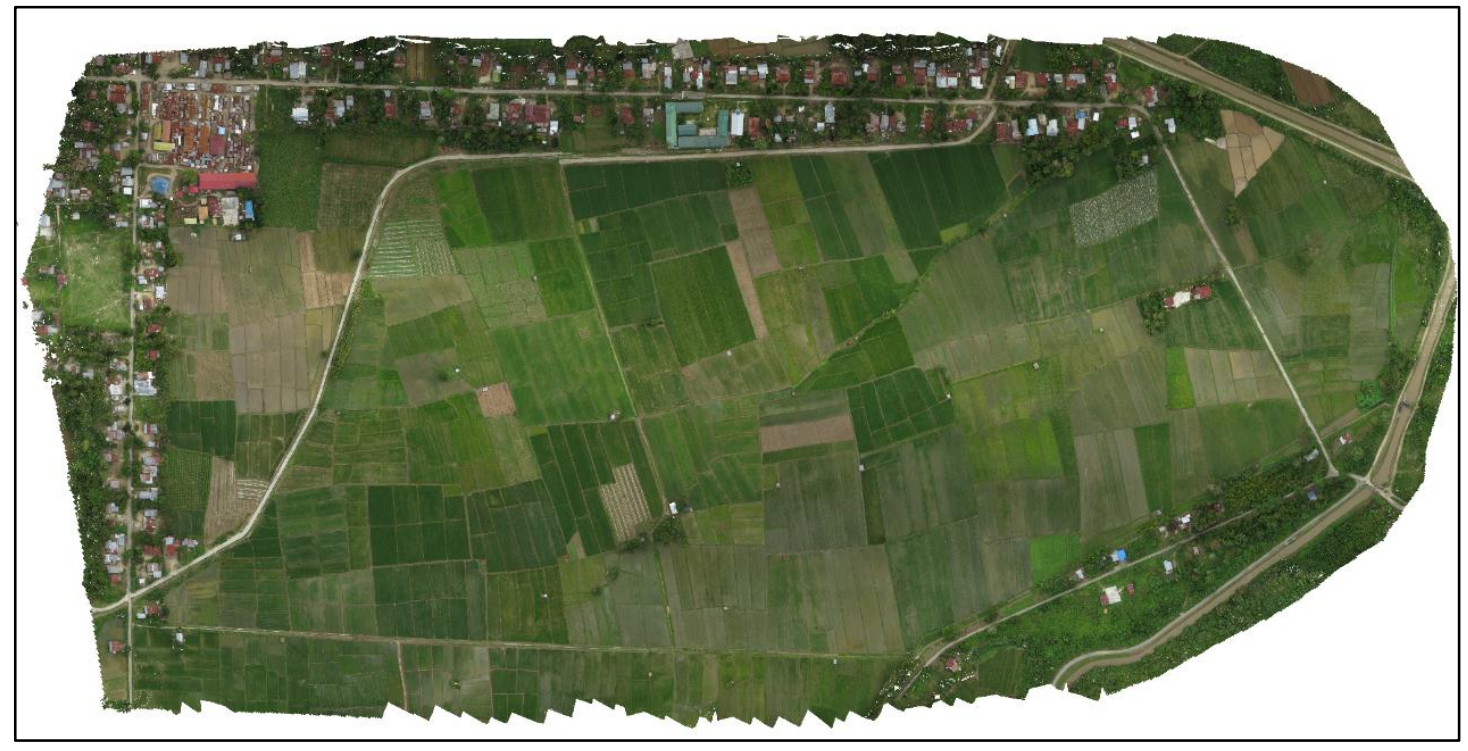

Figure 4. Image produced by Red-Green-Blue camera (True Color Composite) 


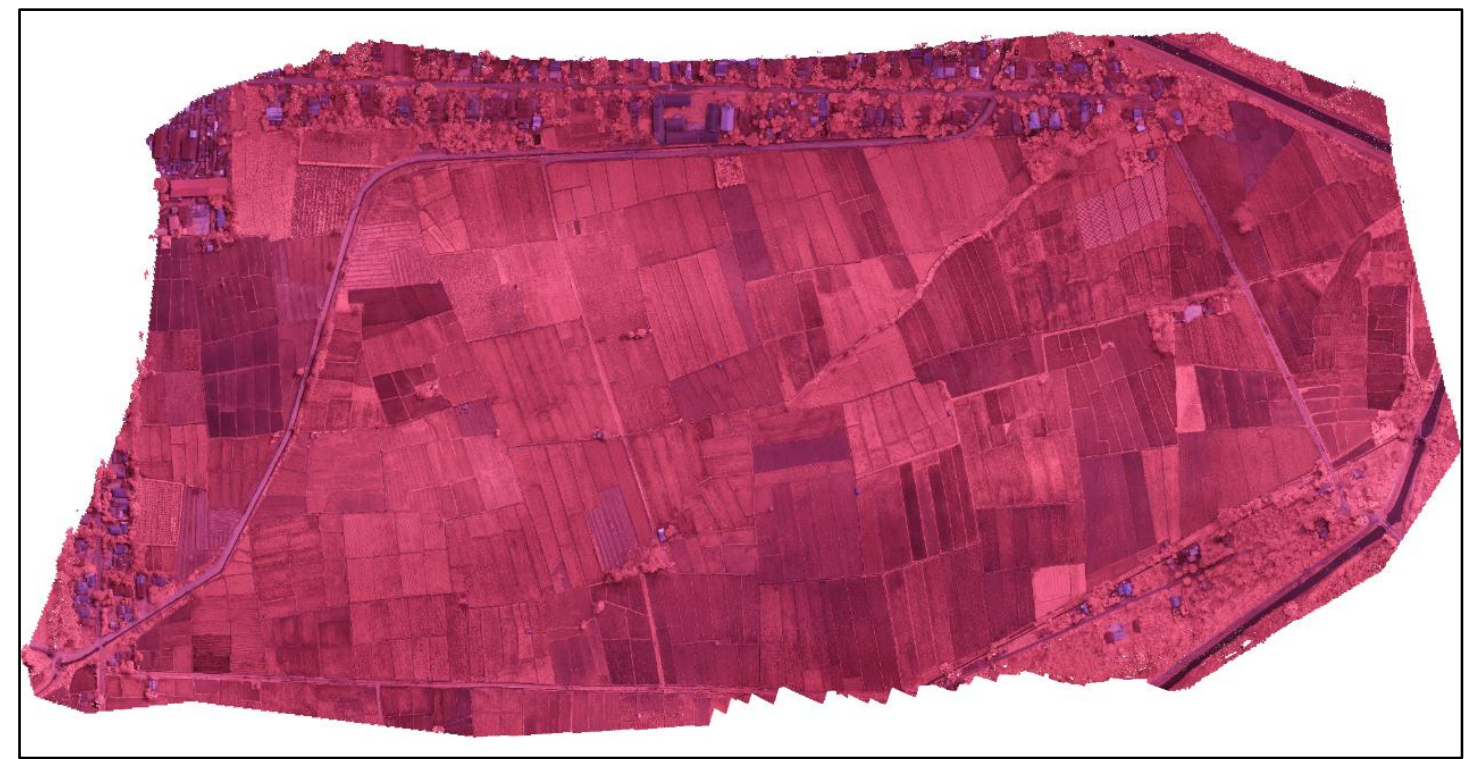

Figure 5. Image produced by Near Infra Red-Green-Blue camera (False Color Composite)

\section{CONCLUSION}

The use of micro-UAV provide an efficient way to collect data needed to manage a very large irrigation systems. The RGB image can be effectively used to identify crop's condition on an irrigation area which is needed to plan irrigation efficiently. The NirGB image can be effectively used to assess tertiary and secondary level of irrigation canal such as leakage.

\section{REFERENCES}

Acevo-Herrera, R., Aguasca, A., Bosch-Lluis, X., Camps, A., Martínez-Fernández, J., Sánchez-Martín, N., \& Pérez-Gutiérrez, C. (2010). Design and First Results of an UAVBorne L-Band Radiometer for Multiple Monitoring Purposes. Remote Sensing. doi:10.3390/rs2071662

Berni, J. A. J., Zarco-tejada, P. J., Suárez, L., González-dugo, V., \& Fereres, E. (2009). Remote Sensing of Vegetation From UAV Platforms Using Lightweight Multispectral and Thermal Imaging Sensors. In C. Heipke, K. Jacobsen, S. Müller, \& U. Sörgel (Eds.), ISPRS Archives, Vol XXXVIII-1-4-7/W5 High-Resolution Earth Imaging for Geospatial Information. Hannover, Germany: ISPRS.
Guo, T., Kujirai, T., \& Watanabe, T. (2012). Mapping Crop Status From An Unmanned Aerial Vehicle For Precision Agriculture Applications. In International Archives of the Photogrammetry, Remote Sensing and Spatial Information Sciences, Volume XXXIX-B1 (Vol. XXXIX, pp. 485-490). Melbourne: ISPRS.

Huang, Y., Fipps, G., Maas, S. J., \& Fletcher, R. S. (2010). Airborne Remote Sensing For Detection of Irrigation Canal Leakage. Irrigation and Drainage, 59(5), 524-534. doi: 10.1002/ird.511

Huang, Y., Thomson, S. J., Hoffmann, W. C., Lan, Y., \& Fritz, B. K. (2013). Development and prospect of unmanned aerial vehicle technologies for agricultural production management. Int. J. Agric. \& Biol. Eng., 6(3), $1-10$. doi:10.3965/j.ijabe.20130603.001

Pasandaran, E. P., Simatupang, \& Faqi, A. M. (2006). Perspective of Rice Production in Indonesia. In Sumarno, Suparyono, A. M. Faqi, \& M. O. Adhnyana (Eds.), Rice Industry Culture and Environment. Subang: Indonesian Center for Rice Research. 